\title{
Supplementary Table 7
}

Phenotypes Associated with Genes in Clusters

\begin{tabular}{|c|c|c|c|c|c|c|c|c|c|c|}
\hline Cluster \# & $\begin{array}{l}\text { Number } \\
\text { of genes } \\
\text { in cluster }\end{array}$ & $\begin{array}{l}\text { Number } \\
\text { annotated } \\
\text { with a wing } \\
\text { phenotype }\end{array}$ & $\begin{array}{l}\text { Number } \\
\text { with RNAi } \\
\text { phenotype }^{@}\end{array}$ & \# lethal ${ }^{@}$ & $\begin{array}{l}\text { \# } \\
\text { Bristle }\end{array}$ & $\begin{array}{l}\text { \# Bristle } \\
\text { morpho- } \\
\text { logy }^{9}\end{array}$ & \# color & \# Notum $^{@}$ & \# PCP ${ }^{@}$ & $\begin{array}{l}\text { \# genes only in } \\
\text { insects or } \\
\text { arthropods }\end{array}$ \\
\hline 1 & 347 & $117(.34)$ & $\begin{array}{ll}89 & (.26)\end{array}$ & $(.09)$ & $50 \quad(.14)$ & (.10) & $17 \quad(.05)$ & $47 \quad(.14)$ & $10 \quad(.03)$ & $(.23)$ \\
\hline 2 & 347 & $125(.36)$ & $101(.29)$ & $(.14)$ & $56 \quad(.16)$ & (.12) & $14 \quad(.04)$ & $47 \quad(.14)$ & $8 \quad(.02)$ & $(.27)$ \\
\hline 3 & 149 & $18 \quad(.12)$ & $25 \quad(.17)$ & $13 \quad(.09)$ & $18(.12)$ & $(.05)$ & $5 \quad(.03)$ & 14 (.09) & $(.01)$ & $\begin{array}{ll}77 & (.52)\end{array}$ \\
\hline 4 & 860 & 319 (.37) & $285(.33)$ & $164(.19)$ & $68 \quad(.08)$ & $14 \quad(.02)$ & $39 \quad(.05)$ & $102(.12)$ & $23 \quad(.03)$ & $129(.15)$ \\
\hline 5 & 276 & $74 \quad(.27)$ & $60 \quad(.22)$ & $22 \quad(.08)$ & $31 \quad(.11)$ & $(.06)$ & $(.04)$ & $34 \quad(.12)$ & $3 \quad(.01)$ & $84 \quad(.30)$ \\
\hline 6 & 832 & 271 (.33) & $229(.28)$ & $119(.14)$ & $128(.15)$ & (.11) & $37 \quad(.04)$ & $124(.15)$ & $17 \quad(.02)$ & $153(.18)$ \\
\hline 7 & 297 & $58 \quad(.20)$ & $63 \quad(.21)$ & $27 \quad(.09)$ & 38 (.13) & $(.09)$ & $(.03)$ & $40 \quad(.13)$ & $5 \quad(.02)$ & $82 \quad(.28)$ \\
\hline 8 & 162 & $28 \quad(.17)$ & $29 \quad(.18)$ & $13 \quad(.08)$ & $12(.07)$ & $(.06)$ & $(.03)$ & $10 \quad(.06)$ & $(.02)$ & $(.60)$ \\
\hline 9 & 652 & 213 (.33) & $227(.35)$ & $115(.18)$ & $118(.18)$ & (.14) & $(.04)$ & $122(.19)$ & $20 \quad(.03)$ & $(.15)$ \\
\hline 10 & 555 & $179(.32)$ & $192(.35)$ & $105(.19)$ & $103(.19)$ & $(.15)$ & $19 \quad(.03)$ & $98 \quad(.18)$ & $13 \quad(.02)$ & $(.18)$ \\
\hline 11 & 89 & $4 \quad(.04)$ & $10 \quad(.11)$ & $3 \quad(.03)$ & $\begin{array}{ll}7 & (.08) \\
\end{array}$ & $(.04)$ & $(.03)$ & $5 \quad(.06)$ & $\begin{array}{ll}0 & (.00) \\
\end{array}$ & $(.62)$ \\
\hline 12 & 89 & $(.08)$ & $(.18)$ & $(.04)$ & $(.08)$ & $(.07)$ & $(.03)$ & $(.09)$ & $(.01)$ & $(.62)$ \\
\hline 13 & 69 & $(.03)$ & $(.10)$ & $(.06)$ & $\begin{array}{ll}6 & (.09) \\
\end{array}$ & $(.09)$ & $(.00)$ & $5 \quad(.07)$ & $(.00)$ & $(.51)$ \\
\hline 14 & 200 & $(.17)$ & $(.22)$ & $(.11)$ & $24 \quad(.12)$ & $(.09)$ & $(.03)$ & $23 \quad(.12)$ & $(.00)$ & $(.40)$ \\
\hline 15 & 31 & $(.10)$ & (.16) & $(.06)$ & $2 \quad(.06)$ & $(.03)$ & $(.00)$ & $3 \quad(.10)$ & $(.00)$ & $(.94)$ \\
\hline 16 & 140 & $18 \quad(.13)$ & $24 \quad(.17)$ & $9 \quad(.06)$ & $14(.10)$ & $9 \quad(.06)$ & $2 \quad(.01)$ & $17 \quad(.12)$ & $1 \quad(.01)$ & $71 \quad(.51)$ \\
\hline total & 5095 & $1469(.29)$ & $1405(.28)$ & $699(.14)$ & $682(.13)$ & $466 \quad(.09)$ & $193(.04)$ & $699(.14)$ & $106(.02)$ & $1318(.26)$ \\
\hline Chi-sq $^{+}$ & & $2 \times 10^{-23}$ & $4.4 \times 10^{-11}$ & $1.2 \times 10^{-11}$ & $3.5 \times 10^{-7}$ & $9 \times 10^{-17}$ & 0.69 & $5.3 \times 10^{-4}$ & 0.29 & $4.2 \times 10^{-81}$ \\
\hline
\end{tabular}

$\wedge$ - data from FlyBase

@ - reference 42 (Mummery-Widmer JL, Yamazaki M, Stoeger T, Novatchkova M, Bhalerao S, Chen D, et al. Genome-wide analysis of Notch signaling in Drosophila by transgenic RNAi. (Nature. 2009;458(7241):987-92.) - For the bristle and notum columns all of the phenotypes in described in that paper were considered.

(fraction of total number of genes in that cluster showing the phenotype)

+ - a chi square test was used to determine if the observed number of genes showing a phenotype was different from that expected if all clusters had an equal frequency of genes producing the phenotype. P values are given. 